\title{
A New Approach of Location Based Routing in MANETs
}

\author{
Priyanka \\ M.Tech Scholar \\ Department of ECE \\ IET Bhaddal
}

\section{PK Gaur}

\author{
Assistant professor \\ Department of ECE \\ IET Bhaddal
}

Lal Pratap Verma

Assistant professor
Department of CSE
SRMIET Ambala

\begin{abstract}
The highly dynamic nature of MANETs results in frequent and unpredictable changes in the network topology, which add to the difficulty and complexity to routing among the mobile nodes within the network. Thus, establishing communication among mobile nodes is a great challenge in itself, resulting in network overloading \& discarding of data packets. Nodes can change position quite frequently, which means we need a routing protocol that quickly adapts to the topology changes which is our objective. In this paper focus has been put on the strategy to address the packet drop ratio which is an integral and important factor of communication in MANETs by minimizing the request zone. In Mobile Ad-Hoc Networks, as the coverage area increases the packet drop ratio also increases which degrades the network performance and Quality of Service (QOS).Location Aware Routing will be used as a base protocol for the proposed work which is a class of Reactive protocol to design optimized routing algorithm.
\end{abstract}

\section{Keywords}

Mobile Ad Hoc Networks, Location Aided Routing (LAR), Energy Efficient Location Aided Routing (EELAR), Route Discovery.

\section{Council for Innovative Research}

Peer Review Research Publishing System

\section{Journal: INTERNATIONAL JOURNAL OF COMPUTERS \& TECHNOLOGY}

Vol 8, No 1

\author{
editor@cirworld.com \\ www.cirworld.com, member.cirworld.com
}




\section{INTRODUCTION}

A MANET is a group of two or more devices or mobile nodes (such as laptops, notebooks) forming an arbitrary network without the help of any permanent infrastructure such as base station or access point. In MANET, every node functions as a router and forwards packets for other peer nodes. There is no fixed topology due to the node mobility, which results in interference, multipath propagation and path loss. Mobile nodes are restricted in battery power, computation capacity, bandwidth, and wireless channel leading to number of challenges while designing routing procedures. Determining viable routing paths and delivering messages in a decentralized environment where network topology fluctuates has always attracted the attention of researchers to design new and new mechanism to solve these problems. While the shortest path (based on a given cost function) from a source to a destination in a static network is usually the optimal route, this idea is not easily extended to MANET.

MANETs Routing protocols are classified into three categories: table-driven, on-demand and hybrid routing protocols. The table-driven routing protocols (DSDV, FSR, CGSR, WRP, and GSR) determine the path to destination before it is needed. On-demand routing protocol (AODV, DSR, TORA, ABR) determines the route to destination when required.

Hybrid routing protocols uses both approaches [6] [8] .The table-driven routing protocols attempts to maintain consistent, up-to-date routing information from each node to every other node in the network. [10]. On-demand routing creates routes only when desired by the source node.

In a mobile ad hoc network, nodes are often powered by batteries. The power level of a battery is finite and limits the lifetime of a node. Every message sent and every computation performed drains the battery. One solution for power conservation in mobile ad hoc network is power awareness routing. This means that routing decisions made by the routing protocol should be based on the power-status of the nodes [7]. Nodes with low batteries will be less preferably for forwarding packets than nodes with full batteries, thus increasing the life of the nodes. A routing protocol should try to minimize control traffic, such as periodic update messages to improve the lifetime of the nodes and network. However, not every routing protocol is suitable for implementing power awareness routing and different approaches on power awareness routing can be followed [11] [12].

The extremely dynamic character of a mobile ad-hoc network (MANET) poses significant challenges on constraints such as minimum hop/distance or low energy. Current routing protocols frequently fails to discover stable routes between source and sink when route availability is transient, e.g. due to mobile devices switching their network cards into lowpower sleep modes whenever no communication is taking place [5].

The Location Aided Routing (LAR) protocols use location information to minimize the Request Zone to reach the destination node. The availability of small, low-power global positioning system(GPS) receivers for calculating relative coordinates make it possible to apply Location-Aided routing algorithms in mobile ad-hoc networks [17]. In the location based routing following parameters are used which are:-

Expected zone: - Consider, source node $S$ wants to send the data packet to destination node D at time T. Assume that $S$ knows the location of $D$ at time Ti. Also it also knows velocity (VD) of $D$ with which $D$ is traveling. Maximum distance traveled by $\mathrm{D}$ in any direction can be calculated as:

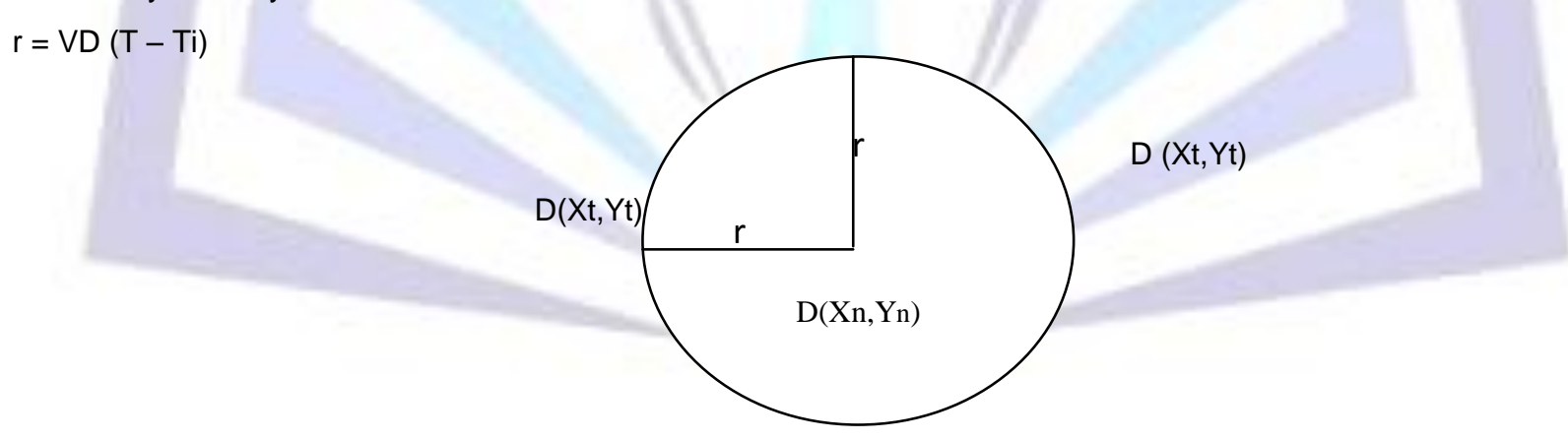

Fig.1.1 Expected Zone

As node is free to move in any direction, so the expected region will be a circular area of radius $D$ as shown in Figure 1.1 .

Request zone: - Request zone is the area where the request packets are sent or broadcast to find a path from source to destination. In the traditional routing algorithms it is the complete network. For e.g. In AODV, DSR, etc. RREQ packet is broadcasted in all directions to find the optimal path from source to the destination node. LAR tries to minimize the request zone by confining it to the smallest rectangular area containing both sender as well as receiver (Figure 1.2). 


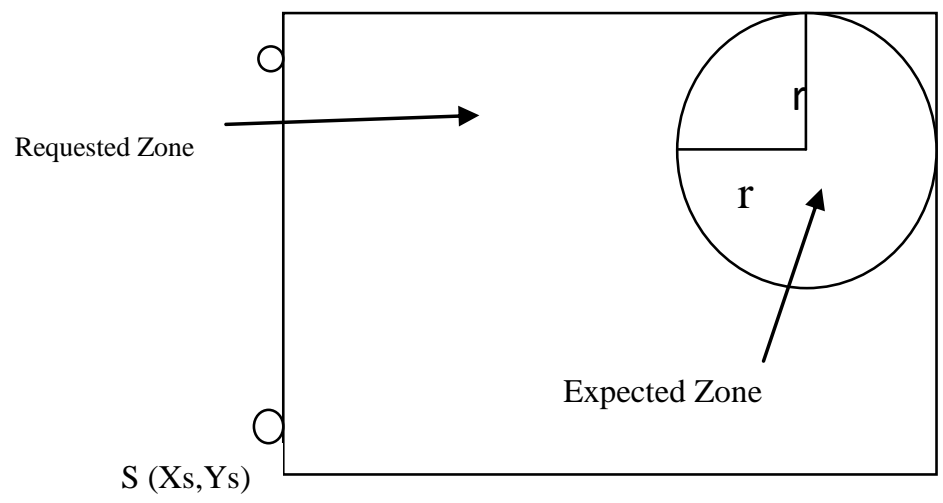

Figure 1.2 Requested zone

Global Position System: - GPS is a system of satellites, ground control stations, and receivers that allows users to determine their position. By capturing and storing that position, GPS receivers "digitize" spatial data as they walk, drive, or otherwise traverse the land. For this reason the term "rover" receiver unit is often used to describe a GPS field receiver. For the sake of consistency, the term "GPS receiver" or "receiver" will be used to identify the GPS "rover" receiver from this point forward. Perhaps the most important characteristic that GIS data developers need to realize about GPS is that it is a highly dynamic system with new satellites being launched and old ones being retired. The constellation of satellites available to users throughout the day is constantly changing as the satellites move through their orbits.

In this paper, we have proposed a New Approach of Location based routing in Manets which reduces the packet drop ratio by minimizing the search area which uses the location information of the mobile nodes to limit the search for a new route to a smaller area of the ad hoc network which can result in a significant decrease in packet drop ratio.

\section{RELATED WORK}

We have many numbers of algorithms which takes into consideration of routing decisions for Location Aided Routing in MANETS.

2.1 Location-Aided Routing (LAR) in Mobile Ad Hoc Networks: In This paper [13] the proposed Location-Aided Routing (LAR) protocols limit the search for a new route to a smaller "request zone" of the ad hoc network. This results in a significant reduction in the number of routing messages. It presented two algorithms to determine the request zone, and also suggest potential optimizations to our algorithms. Simulation results indicated that using location information results in significantly lower routing overhead, as compared to an algorithm that does not use location information.

2.2 Location-Aided Routing (LAR) in Mobile Ad Hoc Networks': This paper [14] suggested an approach to utilize location information (for instance, obtained using the global positioning system) to improve performance of routing protocols for ad hoc networks. By using location information, the proposed Location-Aided Routing (LAR) protocols limit the research for a new route to a smaller "request zone" of the ad hoc network. This resulted in a significant reduction in the number of routing messages. They presented two algorithms to determine the request zone and suggested potential optimizations to their algorithms.

2.3 LABAR: Location Area Based Ad Hoc Routing for GPS-Scarce Wide-Area Ad Hoc Networks: In this paper [15], a new routing algorithm is proposed which requires only a subset of nodes to know their exact location forming location areas around these nodes. This paper outlines the LABAR (Location Area Based Ad Hoc Routing) routing protocol and provides with simulation measurements on its average routing distance compared to the optimum shortest path.

2.4 Energy Efficient Location Aided Routing Protocol for Wireless MANETs: This paper [16] introduced an Energy Efficient Location Aided Routing (EELAR) Protocol for MANETs that is based on the Location Aided Routing (LAR). EELAR makes significant reduction in the energy consumption of the mobile nodes batteries by limiting the area of discovering a new route to a smaller zone. Thus, control packet overhead is significantly reduced. In EELAR a reference wireless base station is used and the network's circular area centre at the base station is divided into six equal sub-areas. At route discovery instead of flooding control packets to the whole network area, they are flooded to only the sub-area of the destination mobile node. The base station stores locations of the mobile nodes in a position table.

2.5 Location-aware routing protocol with dynamic adaptation of request zone for mobile ad hoc networks: This paper [17] proposed a location-based routing protocol called LARDAR. There are three important characteristics be used in our protocol to improve the performance. Firstly, it used the location information of destination node to predict a smaller triangle or rectangle request zone that covers the position of destination in the past. The smaller route discovery space reduces the traffic of route request and the probability of collision. ][=p-0o.-p/[Secondly, in order to adapt the precision of the estimated request zone, and reduce the searching range, we applied a dynamic adaptation of request zone technique to trigger intermediate nodes using the location information of destination node to redefine a more precise request zone. 


\section{PROBLEM FORMULATION}

The highly dynamic nature of MANETs results in frequent and unpredictable changes in the network topology, which add to the difficulty and complexity to routing among the mobile nodes within the network. Thus, establishing communication among mobile nodes is a great challenge in itself. The applications associated with the field of MANETs, make them an important part of the next generation wireless networks. In this proposed research work, focus has been put on the strategy to address the packet drop ratio which is an integral and important factor of communication in MANETs. In Mobile Ad-Hoc Networks, as the coverage area increases the packet drop ratio also increases, thus degrading the network performance and Quality of Service (QOS). This proposed work is a modification of Efficient Location Aided Routing Protocol for Wireless MANETs [16]. It uses location information of the mobile nodes to limit the search for a new route to a smaller area of the ad hoc network which results in a significant decrease in packet drop ratio. We will use Location Aware Routing as a base protocol for the proposed work which is a class of Reactive protocol to design optimized routing algorithm.

\section{PROPOSED WORK}

In this we offer to introduce a New Approach of Location based routing in Manets \& proposed work is divided into following sections.

\subsection{The proposed work will follow the following steps in order to identify the stable path.}

Firstly we will calculate the value of $\mathrm{m}$. If $\mathrm{m}$ lies $\mathrm{b} / \mathrm{w} \mathrm{m} 1$ and $\mathrm{m} 2$ then enter the node id to visited node list and send RREQ to neighbor node. If node id is equal to base station id then it consumes the packet and send RREQ to neighbor node.

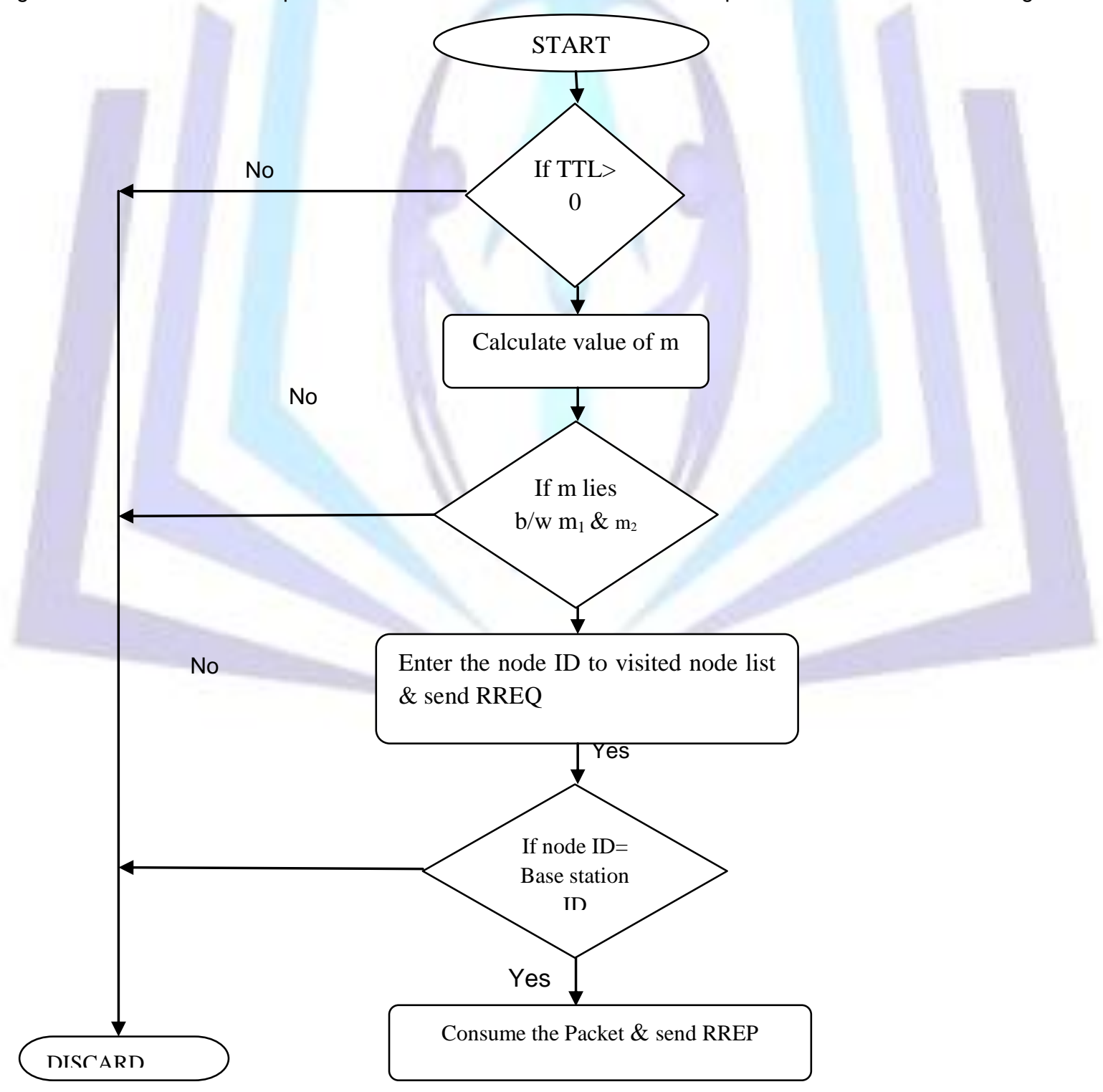

Fig 1.3 Flow Chart 
Else it discards the packet. When base station consumes the packet then it calculates the expected and requested zone on behalf of source. Then again it calculates slopes as mentioned in the above steps. Repeat the step 2 to step 5 and finally destination consume the packet and sends route reply from the same path. The detailed flow chart in fig 1.3 describes the process more clearly.

4.2. Algorithms: The proposed work will utilize the following algorithm in order to find out the best and viable path.

4.2.1. Algorithm for forwarding the RREQ packet from source to Base Station is as follows:

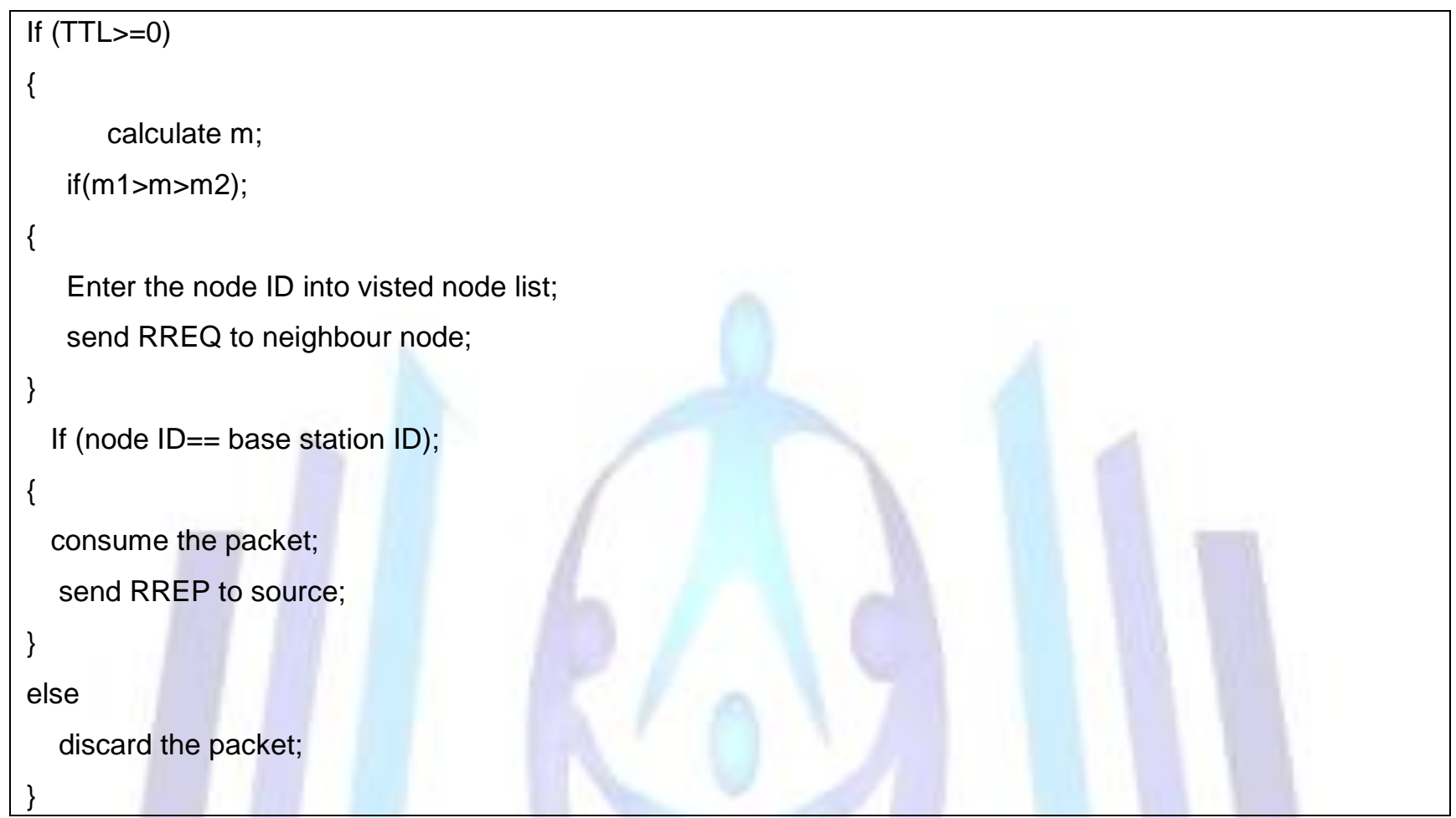

4.2.2. Algorithm for forwarding the RREQ packet from base station to destination:

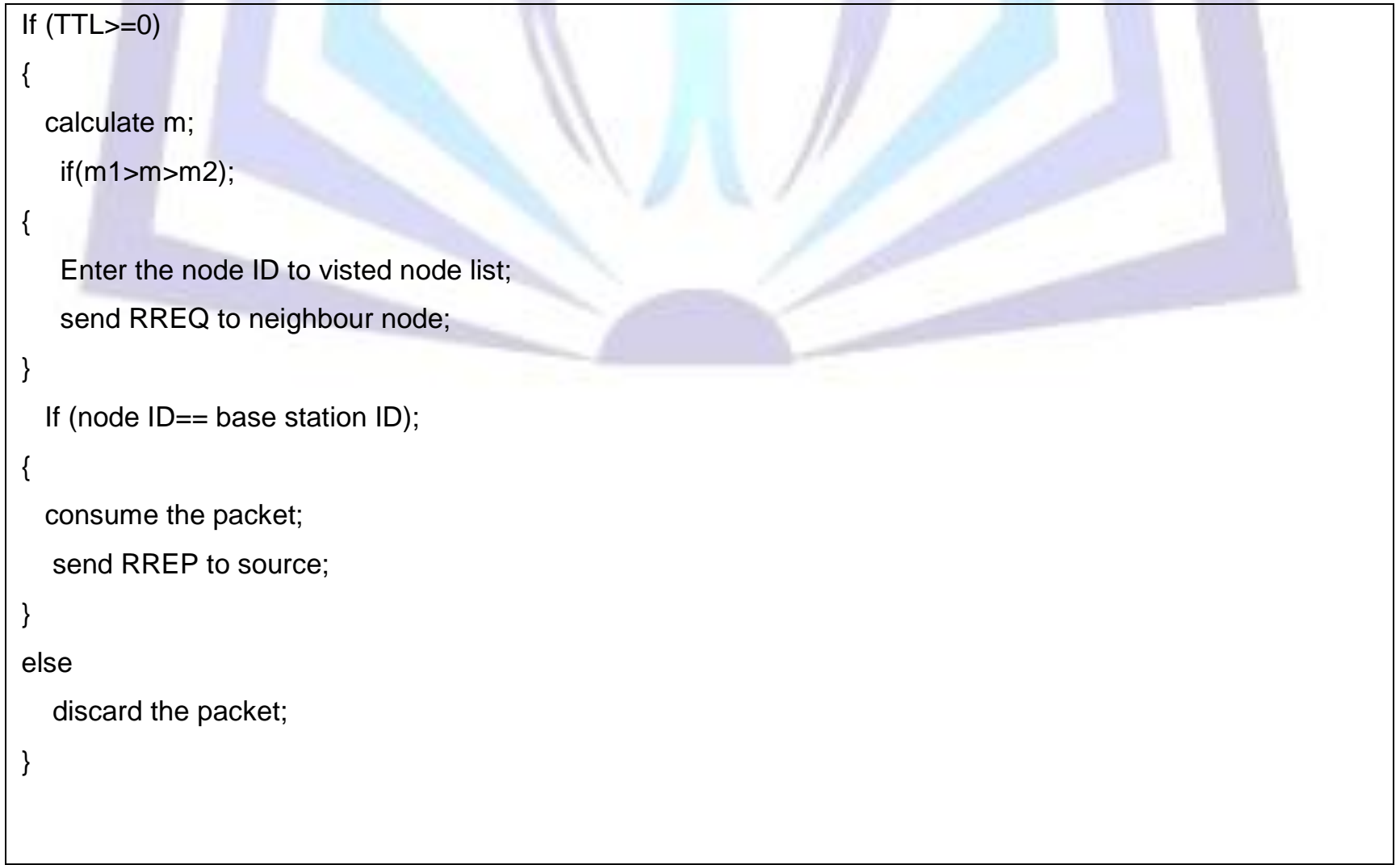




\section{After completion of route:-}

Step 1:-After receiving the route request packet from source, destination node sends acknowledgment to base station. Step 2:- Base station sends acknowledgment to source corresponding to acknowledgment received from destination. Step 3:- Then source sends data packet to destination via base station.

\section{CONCLUSION}

This paper has presented a new protocol "A New Approach for Location Based Routing" which considers both area of routing and bandwidth. In the proposed scheme, messages can be transmitted in a request zone based on the minimum, maximum slope limit by reducing the search area at the time of route discovery. The focus has been put on the strategy to address the packet drop ratio which is an integral and important factor of communication in MANETs which will help in reduction in flooding of RREQ packet and in turn also helpful in reduction in bandwidth consumption. Power consumption can also be considerably reduced by it. In future work, we can also further minimize the power consumption because in this proposed work we are using GPS which consumes more power.

\section{REFERENCES}

[1] Monteiro, A. Goldman, A. Ferreira, "Performance Evaluation of Dynamic Networks using an Evolving Graph Combinatorial Model", IEEE International Conference on Wire-less and Mobile Computing, Networking and Communications, 2006 .

[2] Carla F. Chiasserini, Ramesh R. Rao, "A Distributed Power Management Policy for Wireless Ad Hoc Networks", Proceedings of IEEE Wireless Communication and Networking Conference, 2000.

[3] Suresh Singh, Mike Woo, C. S. Raghavendra, "Power-Aware Routing in Mobile Ad Hoc Networks", Proceedings of MobiCom 98 Conference, Dallas, 1998.

[4] D.S. Thenmozhi and M. Rajaram "Contention Aware Multi-hop Stable Routing to Provide Quality of Service Based on Multiple Constraints in Mobile Ad Hoc Networks" European Journal of Scientific Research ISSN 1450-216X Vol.48 No.4 (2011), pp.567579 @ EuroJournals Publishing,Inc. 2011 http://www.eurojournals.com/ejsr.htm

[5] Pramita Mitra, Christian Poellabauer, Shivajit Mohapatra "On Improving Dynamic Source Routing for Intermittently Available Nodes in MANETs" November 8, 2008.

[6] Joseph Polastre, Robert Szewczyk, Cory Sharp, and David Culler. The mote revolution: Low power wireless sensor network devices. In Proceedings of Hot Chips 16: A Symposium on High Performance Chips, Stanford, USA, pages 56\{76. IEEE Computer Society, 2004.

[7] M. W. S. Singh and C. S. Raghavendra. "Power-Aware Routing in Mobile Ad Hoc Networks". International Conference on Mobile Computing and Networking, Proceedings of the4th Annual ACM/IEEE International Conference on Mobile Computing and Networking, pages 181-190, 1998.

[8] B. H. A. Nasipuri, R. Burleson and J. Roberts. "Performance of Hybrid Routing Protocols for Mobile Ad Hoc Networks". Proceedings of the IEEE International Conference on Computer Communication and Networks (ICCCN2001), pages 296-302, 2001.

[9] D. B. Johnson and D. A. Maltz, "Dynamic Source Routing in Ad-Hoc Wireless Networks,"Mobile Computing, ed. T. Imielinski and H. Korth, Kluwer Academic Publishers, pp. 153-181,1996.

[10] V. D. Park and M. S. Corson, "A Highly Adaptive Distributed Routing Algorithm for MobileWireless Networks," Proceedings of INFOCOM '97, April 1997.

[11] S. Singh, M. Woo, and C. S. Raghavendra, "Power- Aware Routing in Mobile Ad Hoc Networks,"Proc. MobiCom '98, Dallas, TX, Oct. 1998.

[12] S. Singh and C. S. Raghavendra, "PAMAS-Power Aware Multi-Access protocol with Signaling for Ad Hoc Networks," ACM Commun. Rev., July 1998.

[13] Young-Bae Ko and Nitin H. Vaidya, "Location-Aided Routing (LAR) in Mobile Ad Hoc Networks", Wireless Networks, vol. 6, pp. 498-502, 2000.

[14] Ko \& Vaidya. "'Location-Aided Routing (LAR) in Mobile Ad Hoc Networks".

[15] Gergely V. Záruba en al., "LABAR: location Area Based Ad Hoc Routing for GPS-Scarce Wide-Area Ad Hoc Networks.

[16] Mohammad A. Mikki. "Energy Efficient Location Aided Routing Protocol for Wireless MANETs". Proceedings of the International Journal of computer science and Information Security, Vol. 4, No.1 \& 2, September 2009.pp 331-337.

[17] Tzay-Farn Shih . Hsu-Chun Yen. "Location-aware Routing Protocol with dynamic adaptation of request zone for mobile ad hoc networks, Wireless Networks, 2000. 